\title{
Processing of near-net-shape dental crowns by conventional alumina slip casting in gypsum mould
}

Baptista, R. ${ }^{*, * * * *}$, Pereira, C.G. ${ }^{* *}$, Marinho, R. ${ }^{* * *}$, Grancho, S. ${ }^{* * *}$, Ferro, A.C. ${ }^{* * * *, * * * * *}$ and Guedes, M. ${ }^{*{ }^{* * * * * *}}$

* Departamento Mechanical Engineering, Escola Superior de Tecnologia de Setúbal, Instituto Politécnico de Setúbal, 2910-761 Setúbal, PORTUGAL.

** Construction and Environment Section, Escola Superior de Tecnologia do Barreiro, Instituto Politécnico de Setúbal, 2839-001 Lavradio, PORTUGAL.

*** Escola Superior de Tecnologia de Setúbal, Instituto Politécnico de Setúbal, 2910-761 Setúbal, PORTUGAL.

**** Departamento Mechanical Engineering, Instituto Superior Técnico, ULisboa, Av. Rovisco Pais, 1049001 Lisboa, PORTUGAL.

****** ICEMS, Instituto Superior Técnico, Av. Rovisco Pais, 1049-001 Lisboa, PORTUGAL.

Email: mafalda.guedes@estsetubal.ips.pt

The slip casting approach to ceramic powder processing consistently produces complex shapes with homogeneous microstructures. Colloidal stabilization minimizes agglomerates, promotes homogeneity and ensures uniform particle distribution throughout the process [1]. In turn, slip casting ensures fast, simple and economic production. Despite these advantages, slip casting is only used in dentistry to fabricate alumina or zirconia blocks that are afterwards processed to final shape by CAD/CAM [2]. Although slip casting in gypsum moulds appears suitable to produce near-net-shape restorations, its use in ceramic crowns processing is hindered by the difficulty in achieving and controlling micrometric tolerances for the thin wall thickness and wall thickness variation, which are essential to avoid internal and marginal crown adaptation misfits. This work reports preliminary results on the development of a reliable and cost-effective slip casting methodology adequate for dental crown processing. Since the capillary force in the mould is the driving force controlling water absorption and casting rate, several processing parameters are tested in order to achieve gypsum moulds with low porosity and permeability, rendering cast alumina bodies with low wall formation kinetics and controlled thin wall thickness. Gypsum suspensions were prepared with 50/50, 60/40 and $70 / 30$ gypsum-to-water weight ratio, using both cold $\left(20^{\circ} \mathrm{C}\right)$ and hot $\left(100{ }^{\circ} \mathrm{C}\right)$ water, either by mechanical or manual stirring. The effect of a binder additive was also evaluated. FEG-SEM was used to characterize gypsum morphology after setting and drying. Attained results were further related with BET, water absorption and surface roughness measurements. The produced moulds were used for the slip casting of an alumina suspension; produced alumina bodies were characterised in the green and sintered state regarding wall thickness and thickness variation.

Mould density increases with increasing gypsum fraction (Fig. 1). The higher total density value (72.6 \pm 0.9 $\%$ DT) was obtained for the $70 \%$-gypsum sample processed with hot water and mechanical stirring. Addition of Duramax B-1000 to this formulation increased the gypsum water absorption ability, open porosity and surface roughness (Fig. 2). However, addition of Duramax amounts below $0.5 \mathrm{wt} \%$ appears to decrease the maximum amount of absorbed water after the early stages of absorption (Fig. 3). This probably results from the effect of the presence of binder on the gypsum microstructure upon setting (Fig. 4), and suggests a route to control mould permeability. Sintered alumina bodies with wall thickness lower than $800 \mu \mathrm{m}$ were successfully cast and demoulded using the produced gypsum moulds. 
[1] Horn, R.G., J. Am. Ceram. Soc., 73, 1117-1135, 1990.

[2] Giordano, R. Compendium, 31, 682-697, 2010.

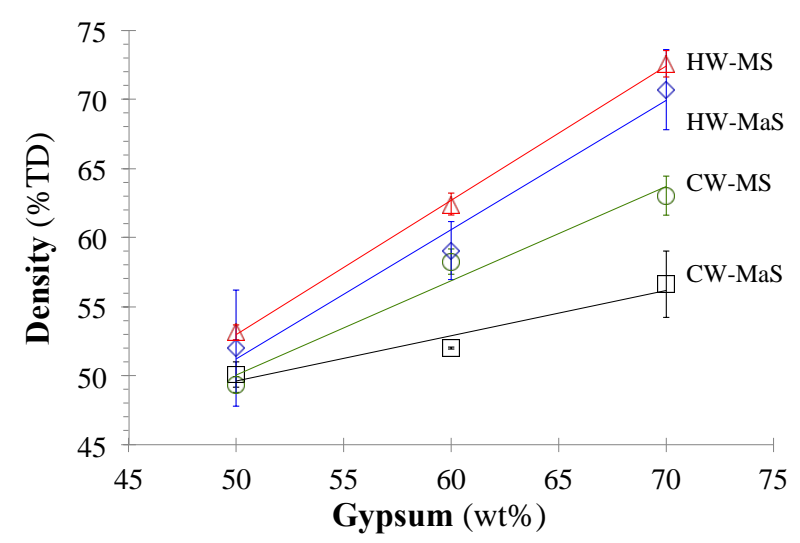

Figure 1. Density of the produced gypsum bodies (HW: hot water; MS: mechanical stirring; MaS: manual stirring).

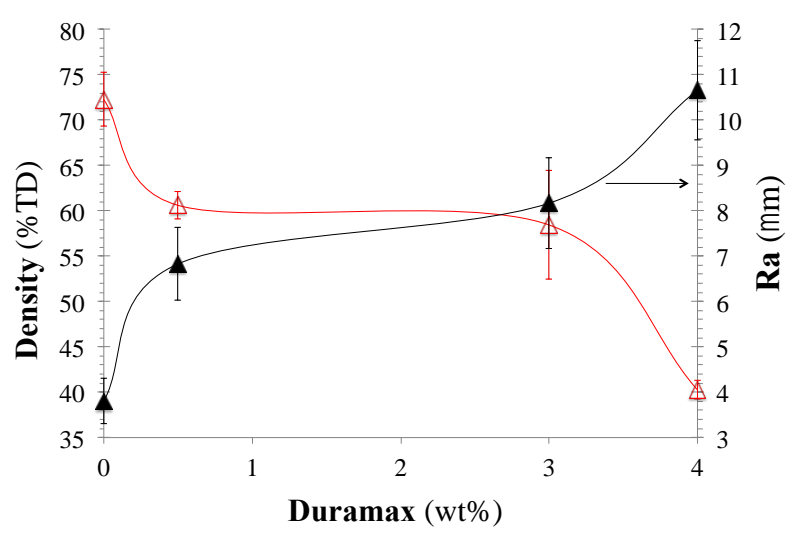

Figure 2. Effect of binder addition upon mould density $(\triangle)$ and surface roughness $(\boldsymbol{\Delta})(70 \mathrm{wt} \%$ gypsum, hot water, mechanical stirring).

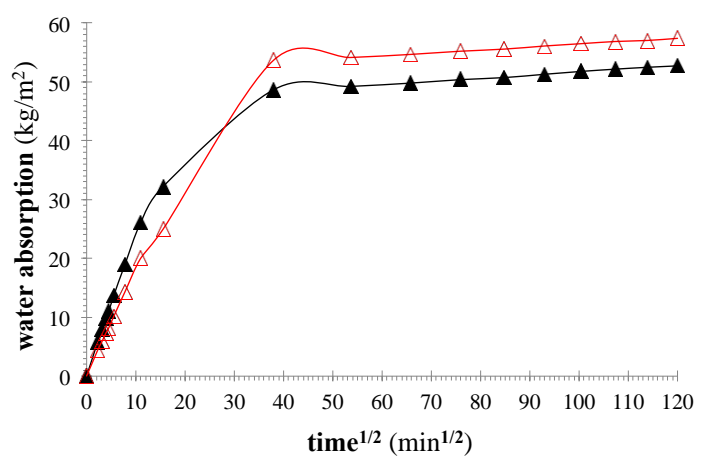

Figure 3. Water absorption kinetics of gypsum mould $(\triangle)$ without and $(\boldsymbol{\Delta})$ with Duramax addition $(0.5$ $\mathrm{wt} \%$ ) (70 wt\% gypsum, hot water, mechanical stirring).
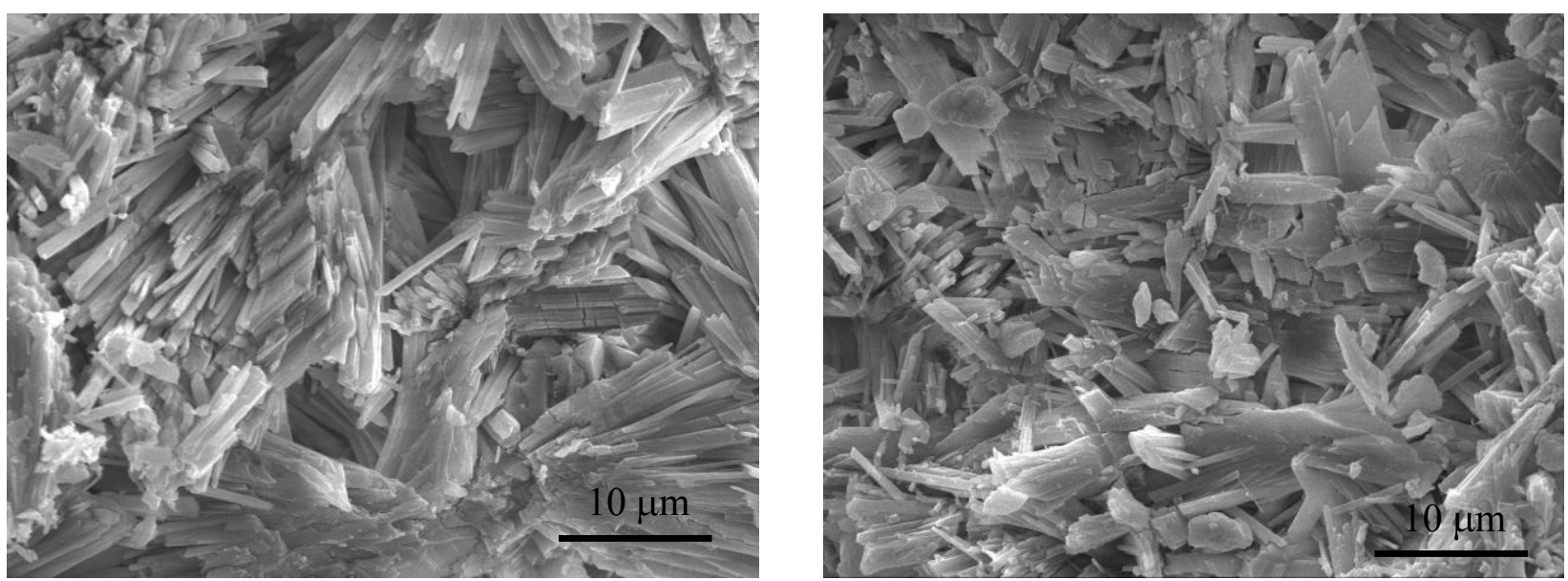

Figure 4. Secondary electron image of gypsum microstructures: (a) $70 \mathrm{wt} \%$ gypsum, hot water, mechanical stirring; (b) with added binder. 